\title{
An Improvement Project - Karma Thailand
}

\author{
Sheng-Pin Kuan \\ The Chinese Society for Quality, Quality Knowledge Community (CSQ/QKC), Taiwan
}

Copyright $(2016$ by authors, all rights reserved. Authors agree that this article remains permanently open access under the terms of the Creative Commons Attribution License 4.0 International License

\begin{abstract}
On the occasion of near my retirement in June 2011, I got a challengeable opportunity to undertake a mission which is applying the integration of diversified improvement technologies for implementing to a Karma factory in Thailand, as we say "SOMA Project" in brief. There are four improvement projects in total: ERP improvement project, stock improvement project, process improvement project, quality improvement project. This report is an interpretation of SOMA Project total process of progression. I just describe the improvement projects concisely, and demonstrate the result of quality project using cloud computing SPC system. Before launching SOMA project, we well organized Karma Taiwan people and Thailand people into 4 project teams, some people join one more teams, engineering people especially. For the SOP sake, we introduced Ford 8D problem solving technique to all the project teams. For the communication sake, we established document center in public website. For the progression control sake, every project team was required to present in every Monday weekly review meeting. For honesty sake, we kept meeting records by photographs and videos. For all Karma group people sake, we mailed weekly report to key man of Karma group in each Saturday. We surveyed and analyzed ERP processes by utilizing Business System Planning methodology to get a systematic result. We surveyed and analyzed stock layout by layout line chart; material picking operation by utilizing process analysis chart to let picking operation more effective. We surveyed and analyzed all the processes of SOMA factory by utilizing plant layout line chart, operation flow chart, material flow chart, process analysis chart. We collected 570 Final Assembly FQC inspection records from January 2011 to May 2011, the FTY average was under 60\%. We deployed 10 more subprojects during our onsite consulting period from June 2011 to December 2011, most of project participants could follow the 8D procedure and got good results. After our onsite consulting, SOMA project keep ongoing till now, we monitor the FTY from cloud computing SPC system, FTY average was $72 \%$ in 2012 , $75 \%$ in $2013,82 \%$ in 2014.
\end{abstract}

Keywords Karma Medical Product Company, 8D Procedure, Business System Planning, FQC, FTY

\section{Project Company Profile}

The motto: "Improve constantly and forever every process for planning, production and service." is one of the famous Deming's 14 Points on Quality Management, a core concept on implementing total quality management, is a set of management practices to help companies increase their quality and productivity, please refers to [1]. The Juran's quality trilogy is a universal approach to managing for quality, consists of three basic quality-oriented processes: quality planning, quality control, and quality improvement, please refers to [2]. Dr. W. Edwards Deming and Dr. Joseph M. Juran are the top quality gurus in the modern quality history, whose continual improvement philosophy have been promoted by the quality professionals and academicians for many decades. The following story is what I applied their philosophy in Karma Thailand.

Karma was established in 1987, Karma is an energetic brand which designs, manufactures, and markets a full range of mobility products worldwide. Karma owns a strong in-house R\&D team committed to providing the best product designs to the elderly and disabled people. We constantly strive to develop and improve our products to meet the market demands. Nowadays, senior citizens and people with physical limitations from more than 40 countries can easily obtain Karma's high quality products and service, including the UK, Europe, Oceania, North America, and Asia, as shown in Figure 1, Global Marketing and Service Network. In these territories, Karma has achieved a very good market position with a great reputation. Together with its products, Karma continues to move forward, offering innovative life enhancement products that enable people to enjoy more active lifestyles and enrich individual's life. 


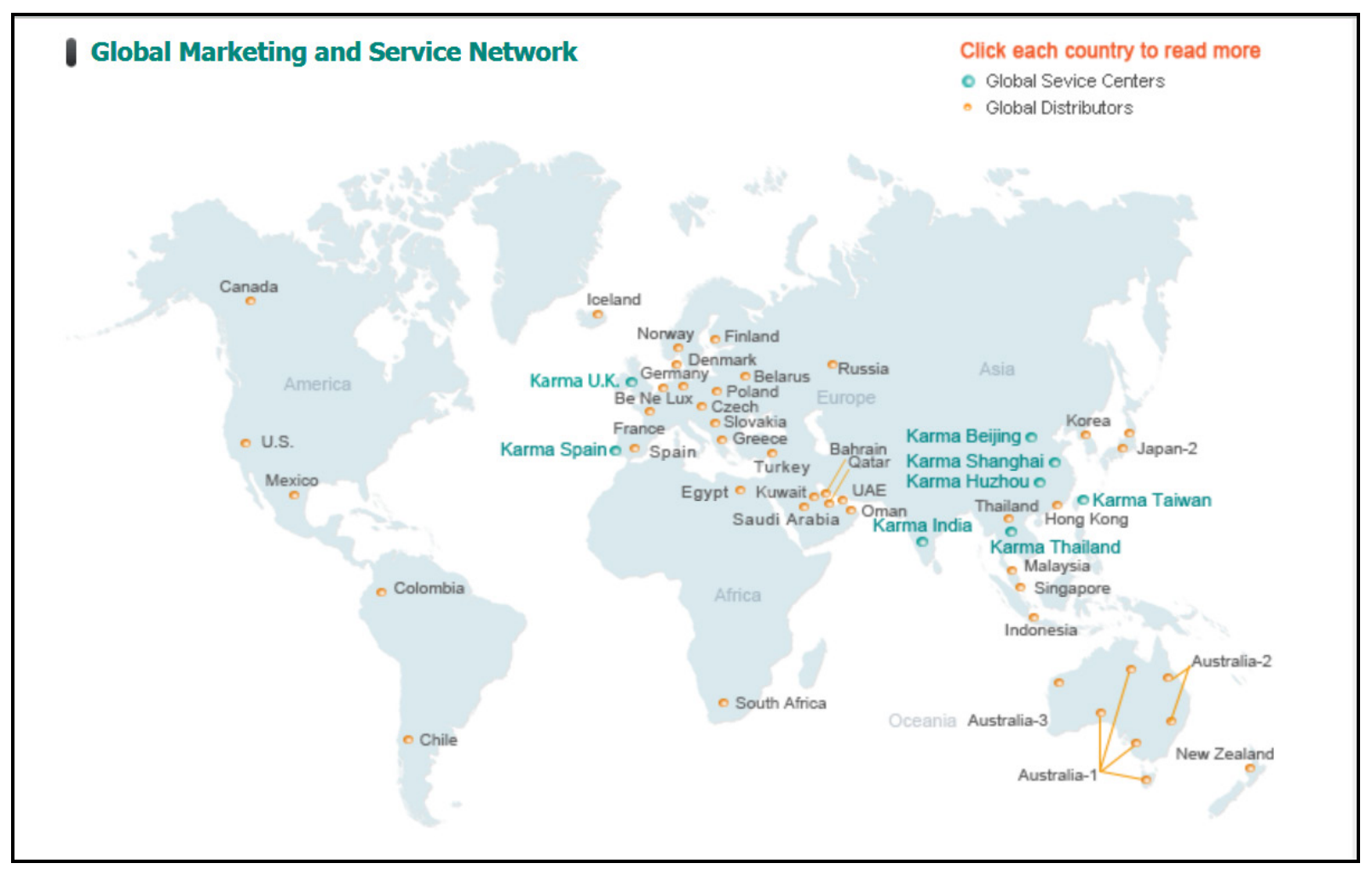

Figure 1. Karma Global Marketing and Service Network (http://www.karmamedical.com/global.php )

As a Karma production base in Thailand, our main focus is on reducing production costs and achieving economics of scale. More importantly, we strive to provide additional added value to Karma headquarters as it continues to grow and expand its business.

While we continue to improve production efficiency and effectiveness to respond to the ever-increasing orders, we never compromise our practice of total quality management. Producing safe and reliable mobility products and helping users avoid secondary injuries remains our key focus.

Moreover, emphasizing the serviceability concept and easy-to-unpack packing by Karma Thailand has offered extra value and convenience for the users. We assemble and package our products in such a way that when unpacked, they are ready to use. By adhering to these principles, we have been able to support Karma brand development in many ways.

The improvement project was held in Karma Thailand, as shown in Figure 2 Karma Thailand, please refer to the website http://www.karmamedical.com/global.php?act=thailand [3].

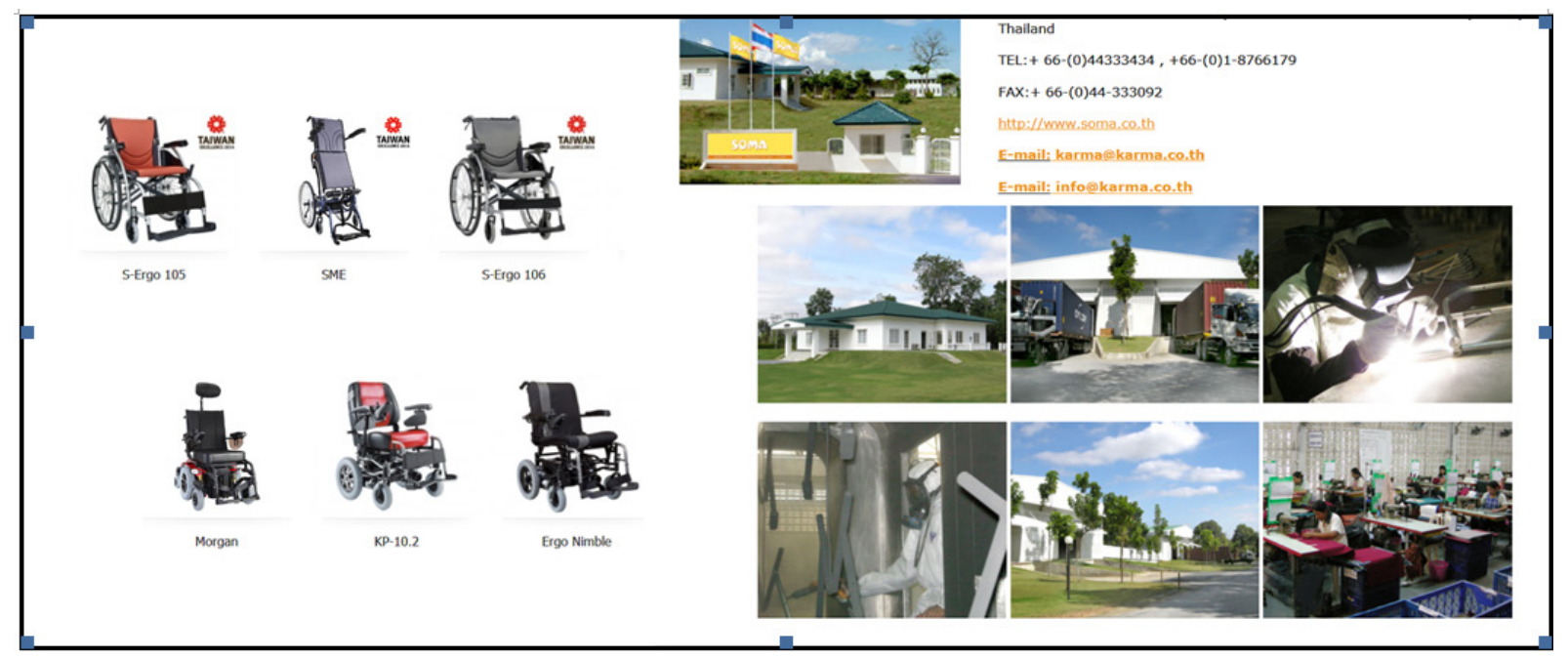

Figure 2. Karma Thailand (http://www.karmamedical.com/global.php?act=thailand ) 


\section{ERP project}

We surveyed ERP processes and programs SOP in the beginning of project, by utilizing data "Input Process Output Analysis" to create a U-C chart for relating processes and data classes. And then we used these tools to modify "SOMA Information Architecture ERP", please refer to the example shown in Figure 3. From these information technologies we can re-edit ERP processes and programs SOP as a guidebook for the users of SOMA ERP. Next, we established an audit system and assigned an authorized people to check all the ERP operations are as ERP SOP say. Finally, we introduced Microsoft Project 2007 for scheduling and controlling all actual order processes and all the production processes. All the result please refers to S.P. Kuan and W.L. Shi [4].

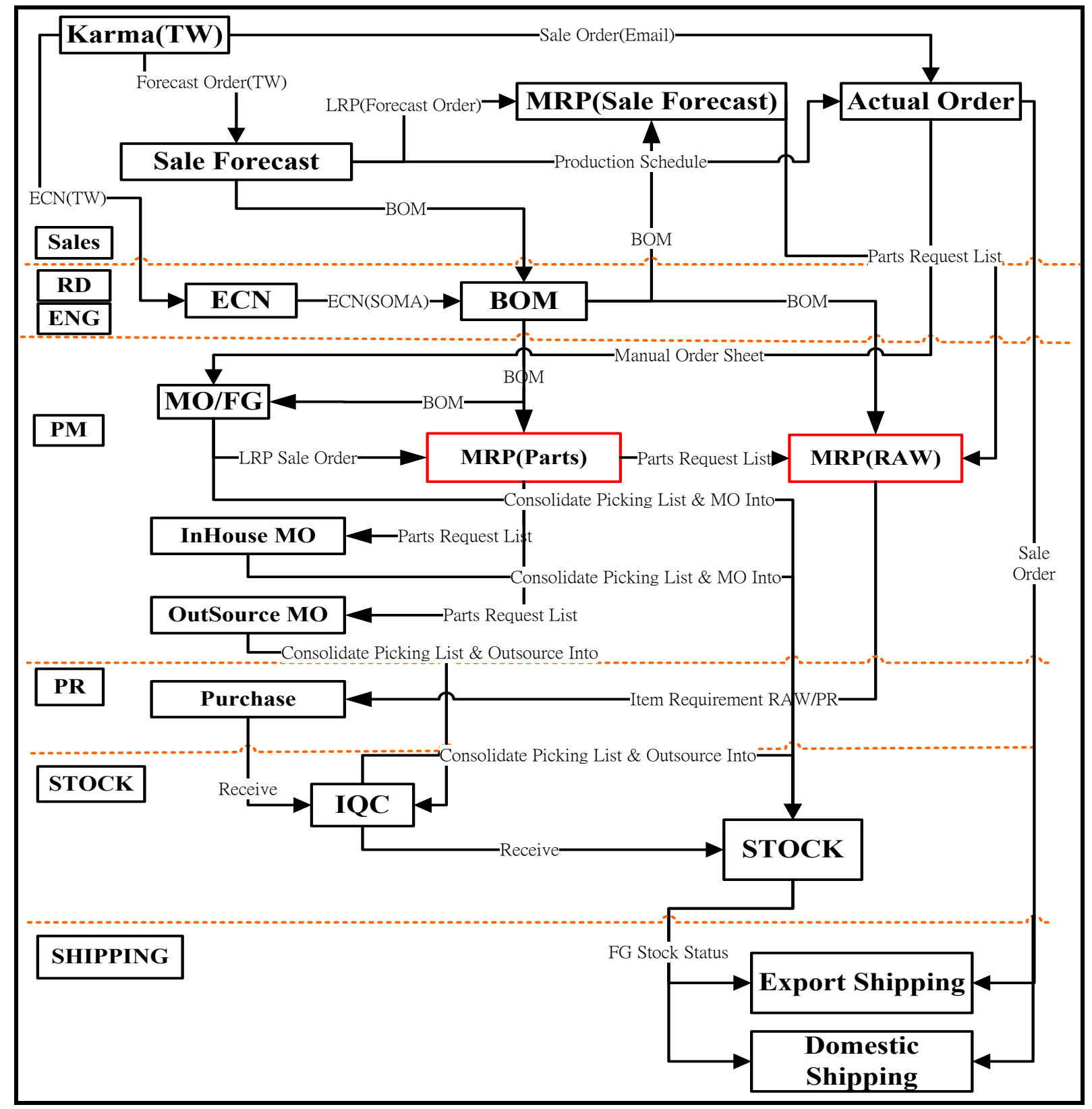

Figure 3. SOMA Information Architecture of ERP 
The main purposes of business information process improvement is running the database accurately, transferring database efficiently and changing business operations real time. The procedures are as following:

(1) Define the scope of business model information process;

(2) Survey the AS IS of business model information process;

(3) Review SOP of each process;

(4) Analyze input and output data of each process;

(5) Draw U-C Chart;

(6) Rename each process and data;

(7) Draw Information Architecture Chart;

(8) Improve SOP of each process;

(9) Improve SOP of each program;

(10) Create audit system;

(11) Planning the TO BE of business model information process.

No matter how powerful the ERP software system is, if the database were inaccurate in the system, we would always make wrong decisions on the information ERP system offering. So the most important things for running ERP system are maintaining an accurate database. SOMA ERP project not only follow up formal information technologies, but also link up Stock Project and Process Project to assure all basic and transactional data are accurate.

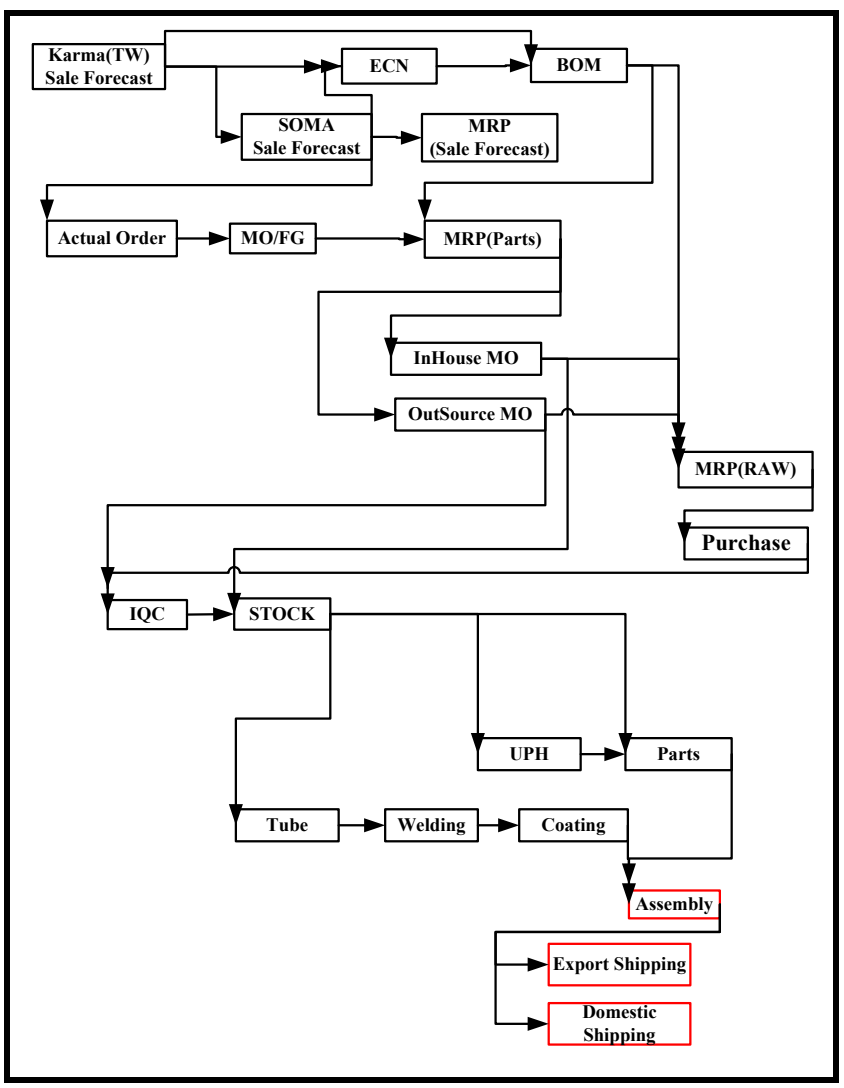

Figure 4. PERT chart of an actual order

We deployed an actual order which received from Karma Taiwan by the PERT chart, shown as Figure 4. It demonstrates all the tasks should be finished accurately and punctually, or the shipment of actual order will make a big trouble. Especially, the First Time Yield (FTY) of assembly line of mobility products is higher means that shipping is in order, in other word; the production system of Karma Thailand is much efficient and effective. Therefore, we focused on the key value of Karma Thailand to every SOMA Project participants; all the indirect departments (Engineering, MIS, Production Control and Quality), and direct departments (Tube, Welding, Coating, UPH and parts) have to service assembly line like as customer.

We surveyed FQC data of Final Assembly Line which was recorded in Excel files, the FTY and Pareto chart of defects from January 2011 to May 2011 are shown as Figure 5. The FTY average was under $60 \%$, it is the reason why I undertake the mission to do something for the Karma Thailand. After I showed Figure 3: SOMA Information Architecture of ERP and Figure 4: PERT chart of an actual order for all project participants, they could understand what their own responsibility are. Therefore, the four improvement project teams could find what their own problems are.

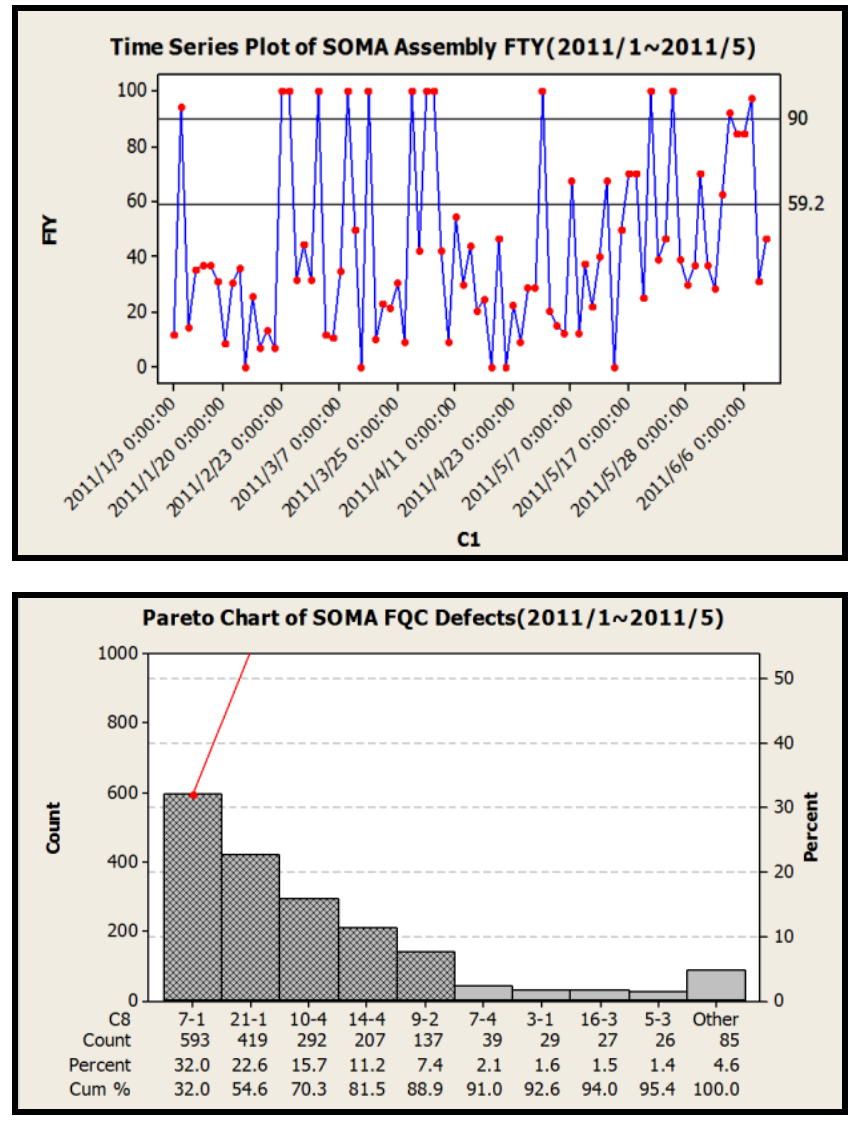

Figure 5. FTY and Pareto chart of defects from January 2011 to May 2011

\section{Process Project}

We surveyed all the processes of SOMA factory by 
utilizing plant layout line chart, flow process chart, material flow chart, flow process analysis chart. When the basic process data which we collected were enough, we analyzed capacity of all processes. We found that the most processes loading are less than theoretical capacity except upholstery sewing process; the reason is most processes are too many material handling and frequencies of change mold. We formed 4 8D improvement projects named as"510 Re-layout","520 Re-layout","530 Line Balance"and"580 Group Sewing", all the result please refers to S.P. Kuan and W.L. Shi [5].

The main purposes of manufacturing process improvement are reduction of process man hours, frequency of material handling, distance of material handling and waiting time for work of operator or machine. The procedures are as following:

(1) Product Quantity Analysis to find which model to be surveyed;

(2) Expand BOM of the model to analyze basic process data for each part;

(3) Draw Plant Layout Line chart for each part;

(4) Draw Flow Process Chart for each part;

(5) Survey Flow Process Analysis Chart for each part;

(6) Calculate Process Capacity Analysis;

(7) Line Balance Analysis;

(8) Draw Man Machine Chart;

(9) Draw Route Map;

(10) Draw From To Chart;

(11) Draw Activity Relationship Line Chart.

These basic process data are not only offer the ERP system to calculate labor cost and wage, but also survey the current process status of the model to improve its processes to be efficient and effective. We just show two of examples by figures. One is the Process Capacity Analysis, the other is Systematic Layout.

\section{Process Capacity Analysis: Model SM100.3, SM150.3 and Caster outer Bracket}

(1) Draw Plant Layout Line chart for each part (Figure 6);

(2) Draw Flow Process Chart for each part (Figure 7);
(3) Survey Flow Process Analysis Chart for each part (Figure 8);

(4) Draw Route Map (Figure 9);

(5) Calculate Process Capacity Analysis (Figure 10).

\section{Systematic Layout: Tube Factory}

(1) Draw Route Map (Figure 11);

(2) Draw From To Chart (Figure 12);

(3) Draw Activity Relationship Line Chart (Figure 13).

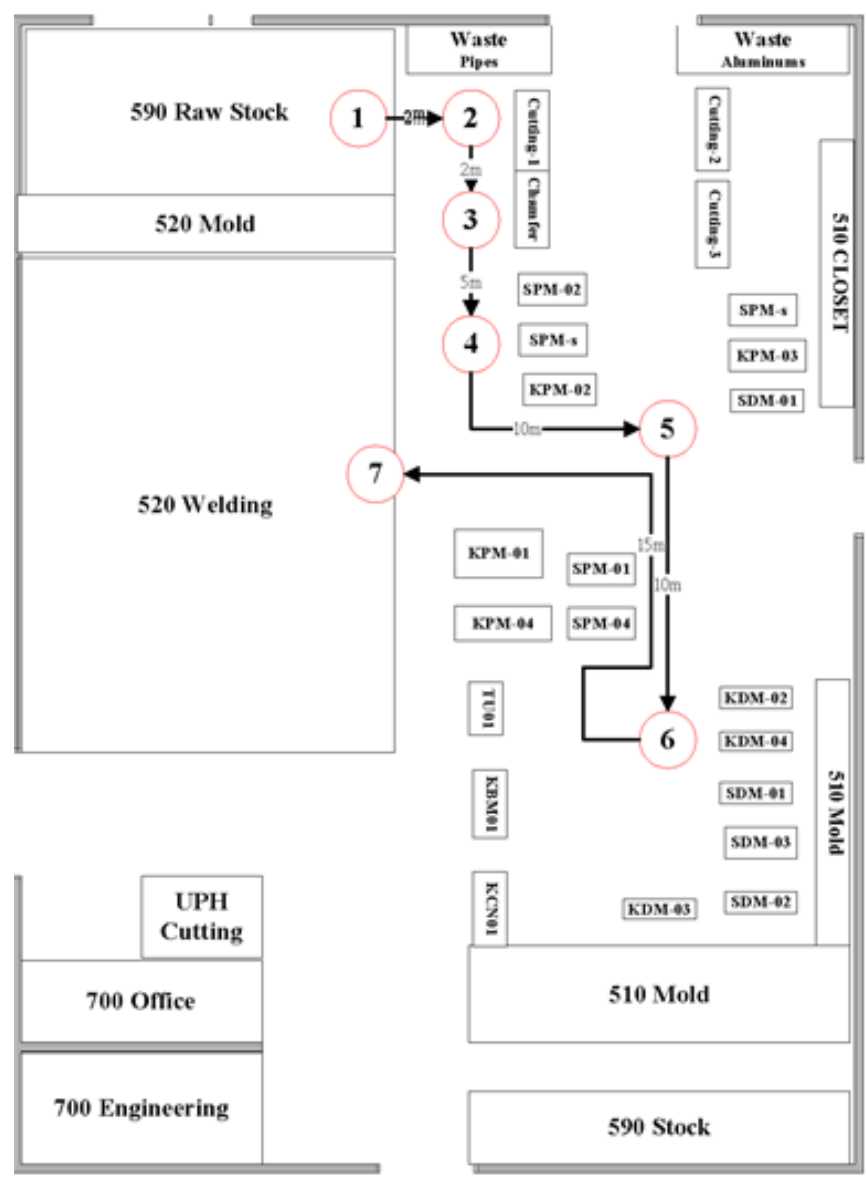

Figure 6. Line chart 


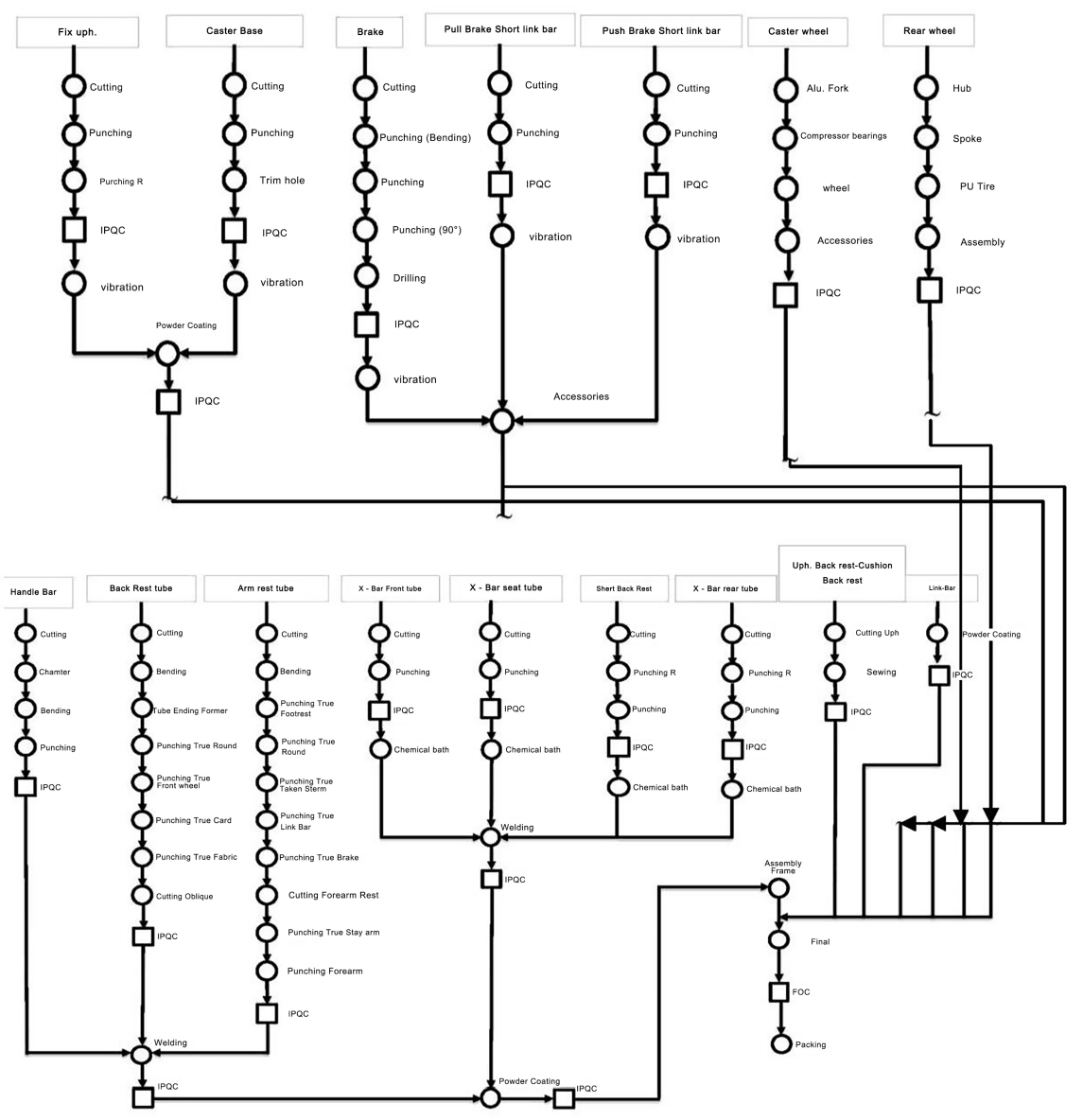

Figure 7. Flow Process Chart

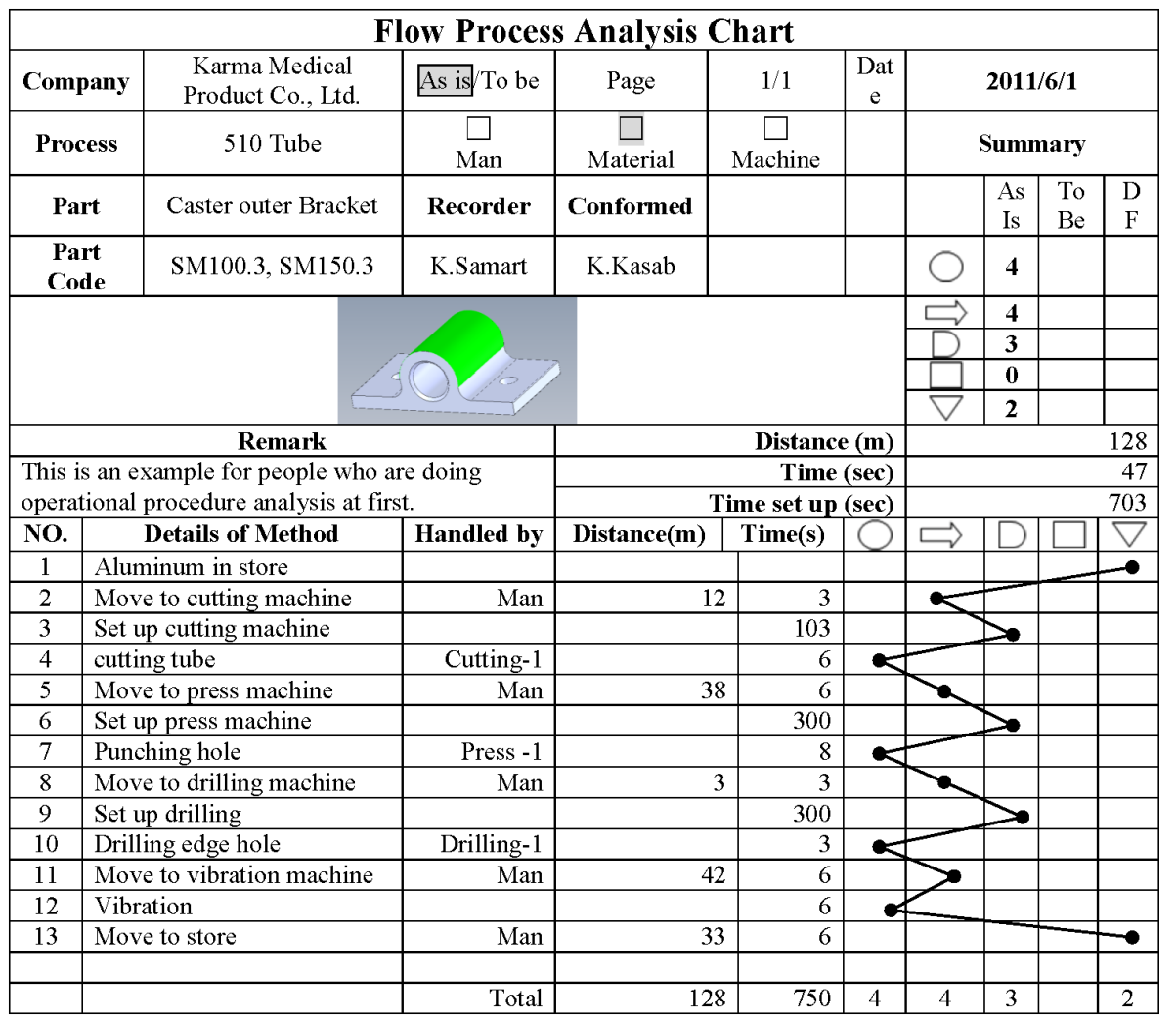

Figure 8. Flow Process Analysis Chart 


\begin{tabular}{|c|c|c|c|c|c|}
\hline \multirow{2}{*}{ Model } & \multirow{2}{*}{ SM 100.3} & Process & Cutting & Bending & Press \\
\hline & & Machine & \begin{tabular}{|l|} 
Cutting-1 \\
\end{tabular} & KCN01 & Press-1 \\
\hline NO. & Parts & QTY & & & \\
\hline 1 & Short backrest L & 1 & (1) & (2) & (3) \\
\hline 2 & Short backrest R & 1 & (1) & (2) & (3) \\
\hline 3 & Seat tube $\mathrm{L}$ & 1 & (1) & (2) & \\
\hline 4 & Seat tube $\mathrm{R}$ & 1 & (1) & (2) & \\
\hline 5 & Front bar L & 1 & (1) & (2) & \\
\hline 6 & Front \& rear bar $\mathrm{R}$ & 2 & (1) & (2) & (3) \\
\hline 7 & Cross bar connect base & 2 & & (1) & (2) \\
\hline 8 & Handle & 2 & (1) & (2) & (3) \\
\hline 9 & Caster Inner Bracket & 2 & (1) & (2) & \\
\hline 10 & Caster outer Bracket & 2 & (1) & (2) & \\
\hline 11 & Brake middle $\mathrm{L}$ bar & 2 & & & (1) \\
\hline 12 & Push brake short link & 4 & & & (1) \\
\hline 13 & Alu Push brake handle & 2 & & & (1) \\
\hline
\end{tabular}

Figure 9: Route Map

\begin{tabular}{|c|c|c|c|c|c|c|c|c|}
\hline \multirow{3}{*}{$\begin{array}{c}\text { Model } \\
\text { NO. } \\
\end{array}$} & \multirow{3}{*}{$\begin{array}{c}\text { SM } 100.3 \\
\text { Parts } \\
\end{array}$} & \multirow{3}{*}{\begin{tabular}{c|} 
Process \\
Machine \\
QTY \\
\end{tabular}} & \multirow{2}{*}{\multicolumn{2}{|c|}{$\begin{array}{c}\text { Cutting } \\
\text { Cutting-1 }\end{array}$}} & \multirow{2}{*}{\multicolumn{2}{|c|}{$\begin{array}{l}\text { Bending } \\
\text { KCN01 }\end{array}$}} & \multirow{2}{*}{\multicolumn{2}{|c|}{$\begin{array}{c}\text { Press } \\
\text { Press-1 } \\
\end{array}$}} \\
\hline & & & & & & & & \\
\hline & & & Set up(sec) & CT(sec) & Set up(sec) & CT(sec) & Set up(sec) & CT(sec) \\
\hline 1 & Short backrest L & 1 & 30 & 3 & 30 & 8 & 100 & 3 \\
\hline 2 & Short backrest R & 1 & 30 & 3 & 30 & 8 & 100 & 3 \\
\hline 3 & Seat tube L & 1 & 30 & 3 & 30 & 8 & & \\
\hline 4 & Seat tube R & 1 & 30 & 3 & 30 & 8 & & \\
\hline 5 & Front bar L & 1 & 30 & 3 & 30 & 8 & & \\
\hline 6 & Front \& rear bar $\mathrm{R}$ & 2 & 30 & 3 & 30 & 8 & 100 & 3 \\
\hline 7 & Cross bar connect base & 2 & & & 30 & 8 & 100 & 3 \\
\hline 8 & Handle & 2 & 30 & 3 & 30 & 8 & 100 & 3 \\
\hline 9 & Caster Inner Bracket & 2 & 30 & 3 & 30 & 8 & & \\
\hline 10 & Caster outer Bracket & 2 & 30 & 3 & 30 & 8 & & \\
\hline 11 & Brake middle $\mathbf{L}$ bar & 2 & & & & & 100 & 3 \\
\hline 12 & Push brake short link & 4 & & & & & 100 & 3 \\
\hline 13 & Alu Push brake handle & 2 & & & & & 100 & 3 \\
\hline \multirow{2}{*}{\multicolumn{2}{|c|}{ Theoretical Capacity }} & Per Day & \multicolumn{2}{|r|}{28800} & \multicolumn{2}{|r|}{28800} & \multicolumn{2}{|r|}{28800} \\
\hline & & Machine & \multicolumn{2}{|c|}{ Cutting-1 } & \multicolumn{2}{|c|}{ KCN01 } & \multicolumn{2}{|c|}{ Press-1 } \\
\hline \multicolumn{2}{|r|}{ M/O-SM 100.3 需求量 } & 1000 & & & & & & \\
\hline & M/O-SM 100.3 & Loading & \multicolumn{2}{|r|}{39270} & \multicolumn{2}{|r|}{120300} & \multicolumn{2}{|r|}{48800} \\
\hline
\end{tabular}

Figure 10. Process Capacity Analysis 


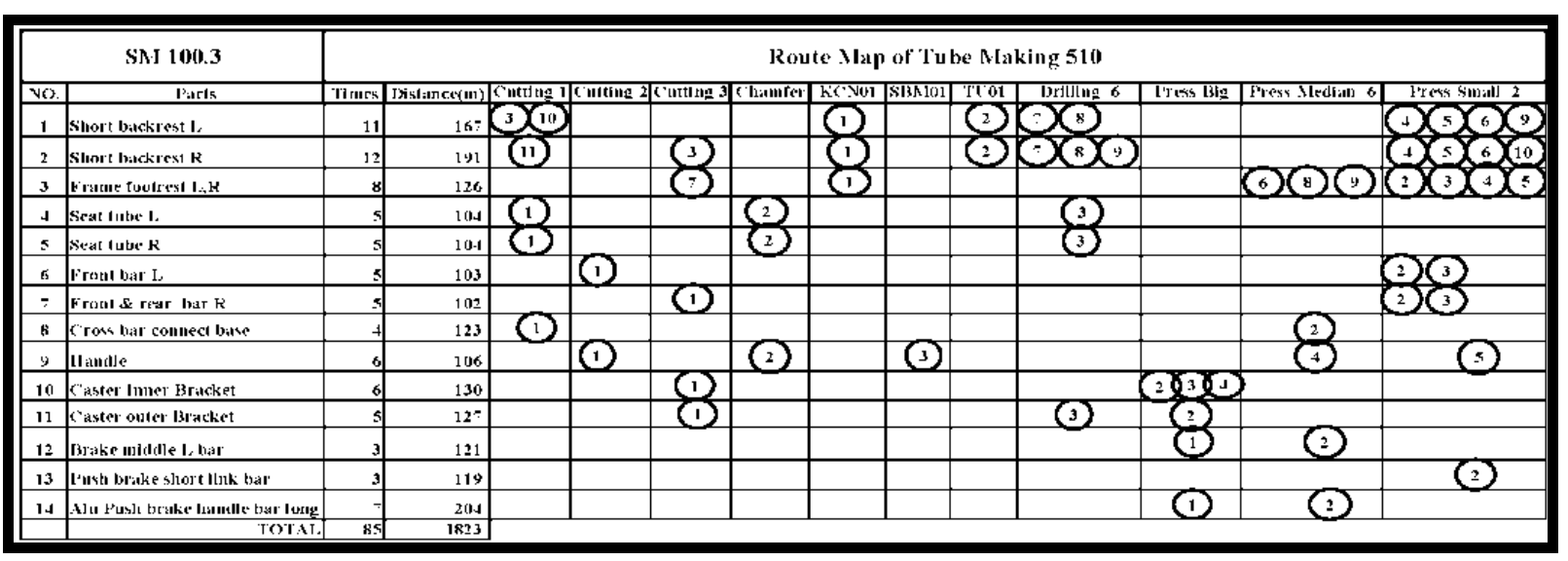

Figure 11. Route Map

\begin{tabular}{|c|c|c|c|c|c|c|c|c|c|c|c|c|}
\hline SM 100.3 & \multicolumn{12}{|c|}{ From TO Chart } \\
\hline FROM & $\frac{n}{6}$ & 言 & 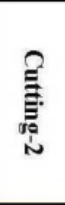 & 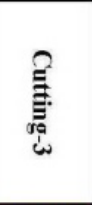 & $\stackrel{?}{\vec{E}}$ & 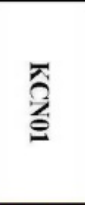 & 苗 & $\vec{\Xi}$ & 总 & 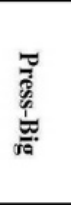 & 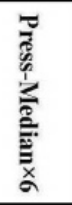 & 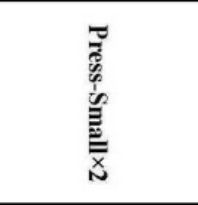 \\
\hline Store & & $\star \star \star \star$ & $\star \star$ & $\star \star \star$ & & $\star \star \star \star$ & & & & $\star \star$ & & $*$ \\
\hline Cutting-1 & & & & & $\star \star$ & & & & & & $\star$ & $\star$ \\
\hline Cutting-2 & & & & & $\star$ & & & & & & & $\star$ \\
\hline Cutting-3 & & & & & & & & & & $\star \star$ & $\star$ & $\star \star$ \\
\hline Chamfer & & & & & & & $\star$ & & $\star \star$ & & & \\
\hline KCN01 & & & & & & & & $\star$ & & & & $\star$ \\
\hline SBM01 & & & & & & & & & & & $\star$ & \\
\hline TU01 & & $\star$ & & $\star$ & & & & & & & & $\star$ \\
\hline Drilling $\times 6$ & & & & & & & & & $\star \star \star$ & & & $\star \star$ \\
\hline Press-Big & & & & & & & & & $\star$ & $\star \star$ & $\star \star$ & \\
\hline Press-Median $\times 6$ & & & & $\star$ & & & & & & & $\star$ & $\star$ \\
\hline Press-Small $\times 2$ & & $\star \star$ & & & & & & & $\star \star$ & & $\star$ & 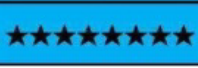 \\
\hline
\end{tabular}

Figure 12. From To Chart

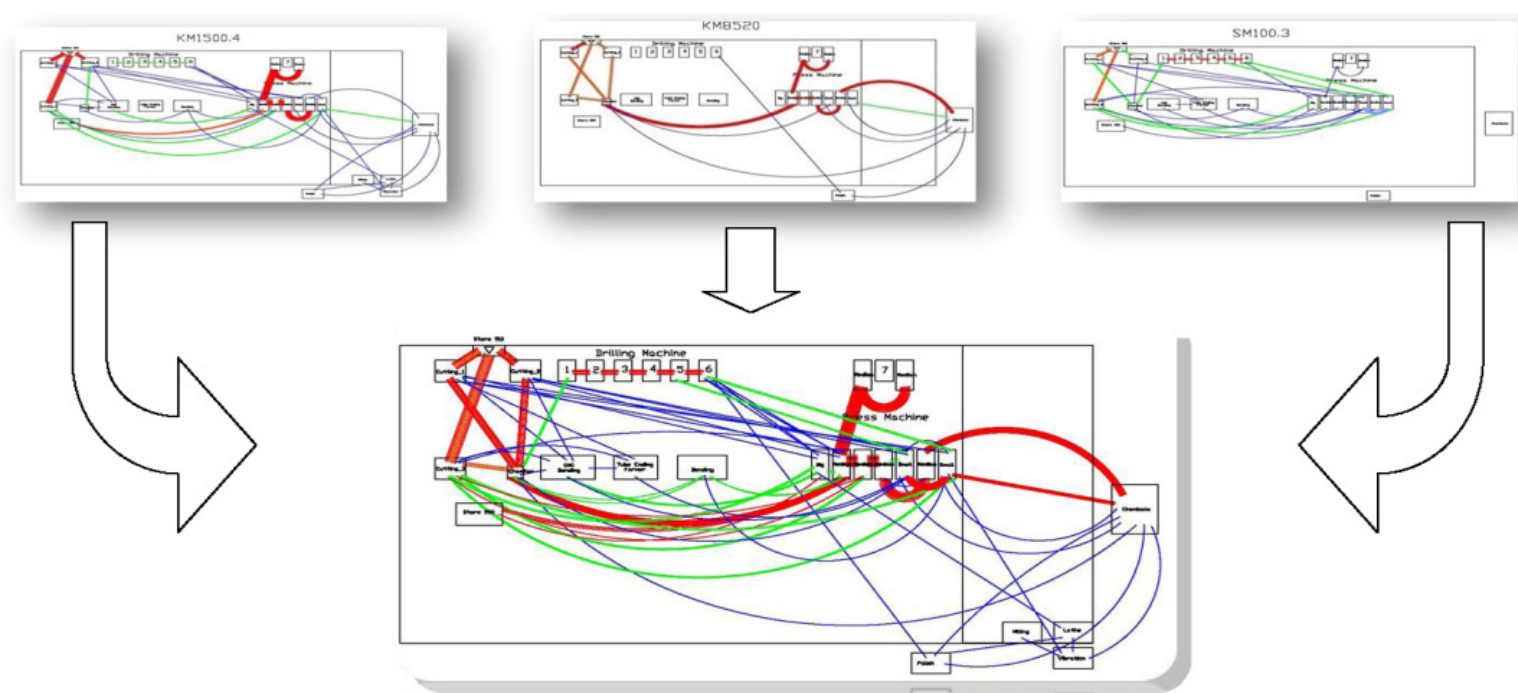

Figure 13. Activity Relationship Line Chart 


\section{Stock Project}

We surveyed ERP processes and programs SOP which are relative with stock management in the beginning of project. We surveyed stock layout by layout line chart; material picking operation by utilizing process analysis chart to understand how long and how far the operators finish one model picking operation. Next, we implemented monthly routine checking stock to understand the status of stock bookkeeping error. And then we analyzed stock level from 2011/1 to 2011/6 monthly to understand total stock amount and categorical stock amount. Finally, we established three improvement projects: "Raising Picking Operation Efficiency", and "Decreasing Stock Level". All the result please refers to S.P. Kuan and W.L. Shi [6].

\section{Quality Project}

We collected final inspection records and analyzed defects by Pareto chart. First, we selected one of the most percentages of defects: out of specification of parallel rear wheel and formed an $8 \mathrm{D}$ improvement project. This $8 \mathrm{D}$ project is the first demonstrative project in SOMA project; we try to teach all the participants understand the whole process of $8 \mathrm{D}$ procedures. We got a good result from three times experiments to verify the root cause of defect. Second, we introduced FMEA( Failure Mode Effect and Analysis) to project team, let team members to survey defect mode, process by process; parts by parts; operation by operation. From these documents of FEMA we can find some significant quality problems, and let project team establish other $8 \mathrm{D}$ improvement projects. After finishing $1^{\text {st }} 8 \mathrm{D}$ project, we chartered $2^{\text {nd }} 8 \mathrm{D}$ project named as "Decreasing Caster wheel out of spec. of SM 802.2", all the result please refers to S.P. Kuan and W.L. Shi [7].

\section{Conclusions}

We had observed SOMA's manufacturing problems in detail for 12 weeks consulting on SOMA site. We found that SOMA got 10 strengths and also 10 weaknesses in total management system. We list it as follows.

\begin{tabular}{|c|c|c|}
\hline & Strengths & Weaknesses \\
\hline $\begin{array}{l}(1) \\
(2) \\
(3) \\
(4) \\
(5) \\
(6) \\
(7) \\
(8) \\
(9) \\
(10)\end{array}$ & $\begin{array}{l}\text { SOMA gets order from Karma Taiwan steadily, and also is a } \\
\text { powerful finish goods and parts supplier for Karma Taiwan. } \\
\text { SOMA gets whole process for finish goods manufacturing. } \\
\text { SOMA gets a smart and active engineering staff. } \\
\text { SOMA gets a strict and industrial FQC staff. } \\
\text { SOMA gets a well established computerized system and well } \\
\text { trained staff. } \\
\text { SOMA gets a group of skillful operational staff. } \\
\text { SOMA gets a group of problem consensus staff. } \\
\text { SOMA gets a group of cohesive staff. } \\
\text { SOMA gets a challengeable problem solving morale. } \\
\text { SOMA gets a group of happy and industrious people. }\end{array}$ & $\begin{array}{l}\text { (1) SOMA lacks whole process of controlling system for supplier } \\
\text { chain. } \\
\text { (2) SOMA lacks strong ECN recommendation position. } \\
\text { (3) SOMA lacks module-like production system. } \\
\text { (4) SOMA lacks a fair incentive system for motivation. } \\
\text { (5) SOMA lacks documentation standard for SOP. } \\
\text { (6) SOMA gets lot of waste for material handling. } \\
\text { (7) SOMA gets lot of waste for waiting. } \\
\text { (8) SOMA gets lot of waste for repairing and adjusting finish goods. } \\
\text { (9) SOMA gets too many bugs in ERP database. } \\
\text { (10) SOMA gets lot of waste for communication. }\end{array}$ \\
\hline \multicolumn{3}{|c|}{ Suggestion } \\
\hline $\begin{array}{l}\text { (1) } \\
(2) \\
(3) \\
(4)\end{array}$ & \multicolumn{2}{|c|}{$\begin{array}{l}\text { Be ambitious utilizing SOMA's strength to get more revenue and profit; be active and practical running 8D to reduce waste and cost. } \\
\text { Develop standard wheelchair modules for manufacturability. } \\
\text { Keep on using 8D project meeting for raising problem solving efficiency. } \\
\text { Keep on holding weekly review meeting for learning each other. }\end{array}$} \\
\hline
\end{tabular}




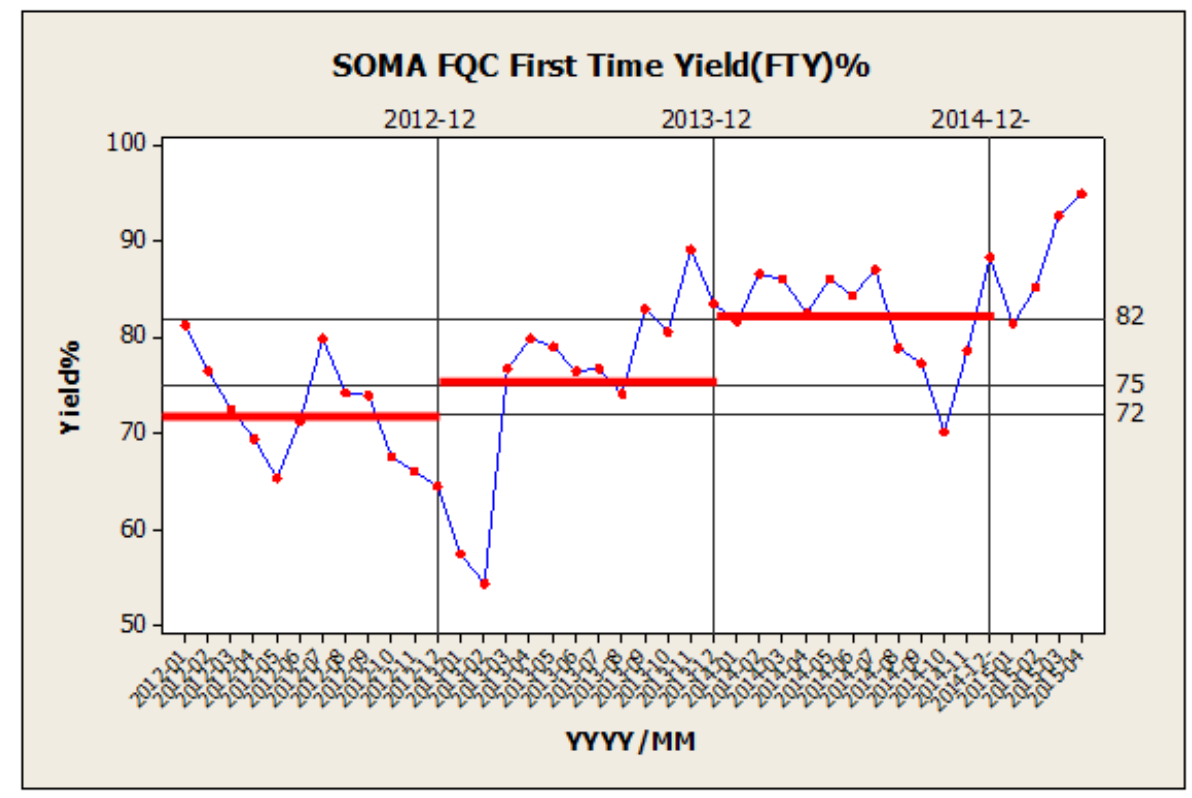

Figure 14. First Time Yield (FTY) \% of SOMA FQC

After our onsite consulting, SOMA project keep ongoing till now, I just monitor the FTY from cloud computing SPC system (http://www.spcwebapps.com/Info/ ), FTY average was $72 \%$ in $2012,75 \%$ in $2013,82 \%$ in 2014 . Especially in recent few months, Karma Thailand staff got an excellent performance; FTY was $88 \%$ in Dec $2014,81 \%$ in January 2015, 85\% in February 2015, 93\% in March 2015, and 95\% in April 2015, are shown as Figure 14. I am proud for that Karma Thailand writes this paragraph on its own website (http://www.karmamedical.com/global.php?act=thailand ): "While we continue to improve production efficiency and effectiveness to respond to the ever-increasing orders, we never compromise our practice of total quality management. Producing safe and reliable mobility products and helping users avoid secondary injuries remains our key focus."

\section{REFERENCES}

[1] http://asq.org/learn-about-quality/total-quality-management/ overview/deming-points.html .

[2] Joseph M. Juran(1986): Universal Approach to Managing for Quality-The Quality Trilogy, Quality Progress August 1986, p.21 p. 24 .

[3] http://www.karmamedical.com/global.php?act=thailand .

[4] S.P. Kuan and W.L. Shi (2011): SOMA ERP Project Technical Report, http://www.kmcloud.org/ .

[5] S.P. Kuan and W.L. Shi (2011): SOMA Process Project Technical Report, http://www.kmcloud.org/ .

[6] S.P. Kuan and W.L. Shi (2011): SOMA Stock Project Technical Report, http://www.kmcloud.org/ .

[7] S.P. Kuan and W.L. Shi (2011): SOMA Quality Project Technical Report, http://www.kmcloud.org/ . 